\title{
Outcome in patients with recurrent restenosis after percutaneous transluminal balloon angioplasty
}

\author{
JAMES J GLAZIER, THOMAS R VARRICCHIONE, THOMAS J RYAN, \\ NICHOLAS A RUOCCO, ALICE K JACOBS, DAVID P FAXON
}

\begin{abstract}
From the Evans Memorial Department of Clinical Research and the Department of Medicine, Boston University Medical Centre, Boston, Massachusetts, USA
\end{abstract}

SUMMARY The records of 1162 consecutive patients undergoing their first percutaneous transluminal coronary angioplasty at a centre between March 1980 and June 1987 were reviewed. Initial angioplasty was successful in 1011 patients (87\%). In $202(20 \%)$ symptomatic restenosis developed. Of these, 196 were treated with redilatation; this was successful in 181 (92\%). After a second dilatation, restenosis developed in 47 patients $(26 \%)$. Of these, $41(87 \%)$ were treated with a third angioplasty, with primary success in $38(93 \%)$. A further restenosis developed in 13 of these 38 patients $(34 \%)$. Eight patients were treated with a fourth angioplasty with restenosis in four $(50 \%)$. Two of these four patients underwent a fifth angioplasty (with continuing success at long term follow up in both). Overall, 14 of the $47(30 \%)$ patients who developed restenosis twice were eventually treated with coronary bypass surgery. Most patients (33), however, were treated only with repeated angioplasties. Of these 33 patients, 27 were treated with a third angioplasty, four with a fourth procedure, and two with a fifth. Twenty-nine $(88 \%)$ were symptom free at a mean follow up of 28 (range 8 to 86 ) months. The combined success rate for a third, fourth, and fifth angioplasty was $94 \%$.

These data suggest that most patients with recurrent restenosis after angioplasty may be managed successfully and safely with repeated redilatations.

Since the introduction of coronary balloon angioplasty a decade $\mathrm{ago}^{1-3}$ the indications for the procedure have widened considerably, the success rate has increased, and the complication rate has fallen. ${ }^{4}$ Despite these impressive advances, restenosis remains the major drawback of the technique, occurring in approximately $30 \%$ of patients who have a successful initial angioplasty. ${ }^{56}$ Treatment of restenosis with a repeat angioplasty is highly successful (greater than $95 \%{ }^{7}$ ). Furthermore, it seems that a second recurrence is no more likely than a first. ${ }^{7-9}$ Accordingly, most physicians recommend a repeat angioplasty for restenosis. ${ }^{8}$ Less, however, is known about the treatment of patients who have a further restenosis after a second angioplasty. With the high annual growth in coronary angioplasty procedures patients with restenosis after a second angioplasty

Requests for reprints to Dr David P Faxon, Section of Cardiology, The University Hospital, Boston, Massachusetts 02118, USA.

Accepted for publication 6 February 1989 will become more common. We report our experience in the management of 47 patients with clinical restenosis after a second angioplasty and the long term outcome in these patients.

\section{Patients and methods}

Between March 1980 and June 1987 a total of 1162 patients underwent coronary angioplasty at our centre. Initial angioplasty was successful in 1011 patients. Clinical restenosis developed in $202(20 \%)$. At our centre, after angioplasty, patients are followed closely by functional testing for the development of symptoms or signs of myocardial ischaemia. If evidence of ischaemia develops, cardiac catheterisation is performed to verify the occurrence of restenosis.

We defined restenosis as the recurrence of angina with angiographic documentation of $>50 \%$ stenosis at a site with primary success. One hundred and ninety six of the 202 patients with clinical restenosis were treated with a second angioplasty procedure. 


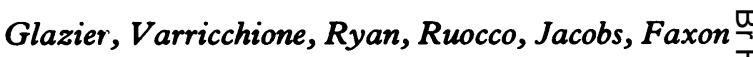

The decision to proceed with a repeat angioplasty was determined entirely by the patient and referring physician. Successful angioplasty (defined as a reduction in diameter stenosis to $<50 \%$ in the absence of myocardial infarction, death, or bypass surgery during hospital stay) was achieved in 181 $(92 \%)$. There was a further recurrence in $47(26 \%)$ of these 181 patients. We studied these 47 patients with recurrent restenosis of a lesion initially treated by angioplasty. Tables 1 and 2 show the clinical and angiographic features in these patients.

\section{FOLLOW UP}

After angioplasty patients attend our centre as outpatients every six months for a physical examination and symptom limited treadmill exercise test. Because the unit is a referral centre for more than twenty community hospitals, a large proportion $(38 \%$ ) of our patients with recurrent restenosis had been followed up at another hospital after their last angioplasty. We established contact with these patients by a postal questionnaire and/or telephone contact in April 1988.

\section{Results}

\section{OBSTRUCTIVE LESIONS}

Sixty four lesions in $\mathbf{4 7}$ patients were successfully dilated at initial angioplasty (table 2) and 55 of these were redilated. Fifty lesions restenosed both after first and second angioplasty. Of these lesions undergoing recurrent restenosis, $26(52 \%)$ were located in the left anterior descending artery ( 10 in the proximal segment), $13(26 \%)$ in the right coronary, $10(20 \%)$ in the circumflex, and one in a graft vessel.

\section{MANAGEMENT OF SECOND RESTENOSIS}

Of the 47 patients with a second restenosis of their

Table 1 Baseline clinical data in the study patients with recurrent restenosis

\begin{tabular}{ll}
\hline Variable & Data \\
\hline Patients (no) & 47 \\
Mean (SD) age (yr) (range) & $54(10)(39-78)$ \\
Men & $41(87)$ \\
Hypertension (>140/>95 mm Hg) & $23(49)$ \\
Cigarette smoking: & $8(17)$ \\
Current & $15(32)$ \\
Former & $23(49)$ \\
Family history CAD & $16(34)$ \\
Hypercholesterolaemia & $24(51)$ \\
Previous myocardial infarction & \\
Angina status (Canadian Heart Association & \\
classification) & $16(34)$ \\
Unstable & $25(53)$ \\
Stable class III-IV & $6(13)$ \\
\hline
\end{tabular}

Numbers in parentheses are percentages. CAD, coronary artery disease.
Table 2 Baseline angiographic data.in the study patients

\begin{tabular}{|c|c|}
\hline Finding & No $(\%)$ \\
\hline $\begin{array}{l}\text { One vessel disease } \\
\text { Two vessel disease } \\
\text { Three vessel disease } \\
\text { Left ventricular ejection fraction (\%) } \\
\text { (SD and range) }\end{array}$ & $\begin{array}{l}26(55 \%) \\
15(32 \%) \\
6(13 \%) \\
64(14)(20-84)\end{array}$ \\
\hline $\begin{array}{l}\text { Location of lesions }(n=64) \text { dilated } \\
\text { (according to vessel): } \\
\text { Left anterior descending } \\
\text { Circumflex } \\
\text { Right coronary } \\
\text { Graft } \\
\text { Single lesion dilatation } \\
\text { Multilesion dilatation }\end{array}$ & $\begin{array}{l}30(\text { proximal }=10) \\
18 \\
15 \\
1 \\
35(74 \%) \\
12(26 \%)\end{array}$ \\
\hline
\end{tabular}

initially angioplastied lesion(s), six chose to be $\stackrel{\text { ? }}{-}$ treated with coronary graft bypass surgery and 410 had a third angioplasty. Angioplasty was successful $b_{\circ}^{\circ}$ in 38 of these 41 patients $(93 \%)$. Of the three patients in whom a third angioplasty was unsuccessful, two developed abrupt reocclusion requiring emergency $\vec{c}$ coronary bypass graft surgery and one had a fatal cardiac arrest 24 hours after the procedure (table 3 ).. Restenosis occurred in $13(34 \%)$ of the 38 patients $\overrightarrow{0}$ who had a successful third angioplasty.

TREATMENT OF A THIRD RESTENOSIS

Eight of the 13 patients with a third restenosis were treated with a fourth angioplasty, four with bypassa surgery, and one with medical management. Initialo success was obtained in all patients with a fourth angioplasty, but restenosis developed in four $(50 \%) \frac{\widehat{\rho}}{3}$ (table 3).

TREATMENT OF A FOURTH RESTENOSIS

Two patients were treated with a fifth angioplasty (successful in both) and two with a bypass operation.

SUMMARY OF RESULTS

Of the 47 patients who developed restenosis twice, 140 $(30 \%)$ were eventually treated with coronary graft bypass surgery (12 electively and two as emergen-윽 cies). Most (33), however were treated only with $\supset$

Table 3 Outcome of patients with restenosis

\begin{tabular}{|c|c|c|c|c|c|c|c|}
\hline$R S$ & $\begin{array}{l}\text { Rate } \\
(\%)\end{array}$ & No & $I^{\circ}$ & $P T C A$ & $E m C A B G$ & $\begin{array}{l}\text { Prim } \\
\text { succ }\end{array}$ & $\begin{array}{l}\text { Sus } \\
\text { succ }\end{array}$ \\
\hline $\begin{array}{l}\text { 1st } \\
\text { 2nd } \\
\text { 3rd } \\
\text { 4th }\end{array}$ & $\begin{array}{l}20 \\
26 \\
34 \\
50\end{array}$ & $\begin{array}{r}202 \\
47 \\
13 \\
4\end{array}$ & $\begin{array}{l}6 \\
6 \\
4 \\
2\end{array}$ & $\begin{array}{c}196 \\
41^{\star} \\
8 \\
2\end{array}$ & $\begin{array}{l}6(3 \%) \\
2(4 \%) \\
0 \\
0\end{array}$ & $\begin{array}{c}181(92 \%) \\
38(93 \%) \\
8(100 \%) \\
2(100 \%)\end{array}$ & $\begin{array}{l}134 \\
23 \\
4(1)+ \\
2\end{array}$ \\
\hline
\end{tabular}

*One patient died.

†One patient treated medically.

RS, restenosis; $1^{\circ} \mathrm{CABG}$, initial treatment with coronary bypass surgery; PTCA, initial treatment with percutaneous transluminal ${ }^{\Phi}$ coronary angioplasty; Em CABG, emergency coronary bypass? surgery; Prim succ, primary success, Sus succ, sustained success $\varrho$ after PTCA. 
repeated angioplasty. Of these 33 patients, 27 had three angioplasty procedures, four had four procedures, and two had five procedures.

\section{FOLLOW UP}

Of the 33 patients treated only with repeated angioplasty (table 3$), 29(88 \%$ ) remain well and angina free at a mean follow up period of 28 (range 8-86) months. In three patients (each treated with three angioplasty procedures) angina has recurred. One of these patients had a myocardial infarction and documentation of a third restenosis of his graft lesion. However, further revascularisation was not attempted in this patient, who has moderate symptoms on medical treatment. The other two patients have mild symptoms which are adequately controlled on medical treatment. In addition, two patients reported occasional atypical chest pain after their last angioplasty. There was no evidence of restenosis, however, in either patient at repeat angiography. Both patients treated with a fifth angioplasty remain well and symptom free with no evidence of inducible ischaemia, as assessed by repeated exercise testing, 15 and 32 months after the last procedure. There have been no late deaths and only the patient mentioned earlier has had a myocardial infarction since the last angioplasty.

Of the 14 patients who were eventually treated with bypass surgery, three $(21 \%)$ have had a recurrence of their symptoms. One of these three patients had a myocardial infarction 10 months after operation. There were no deaths in this patient group at a mean follow up of 27 (range 8-48) months.

\section{Discussion}

Our observations suggest that most patients with recurrent restenosis can be managed safely and effectively with repeated angioplasty. Of the 47 patients with a second restenosis, $33(70 \%)$ were treated only with angioplasty and $29(88 \%)$ were well and symptom free at long term follow up. Furthermore, the primary success rate for a third angioplasty was very acceptable $(93 \%)$, as was the combined success rate $(94 \%)$ for third, fourth, and fifth angioplasties.

Jolly et al reported a similar recurrent restenosis rate $\left(4.3 \%\right.$ in their series ${ }^{10}$ and $4 \%$ in ours). We elected to perform a third angioplasty in most $(87 \%$ ) of our patients with a second restenosis, whereas Jolly et al treated most (58\%) of such patients with coronary bypass surgery. Jolly et al reported that their choice of treatment for patients with a second restenosis seemed to be influenced more by the opinion of the cardiologist and the wishes of the patient than by clinical or angiographic factors, as was the case in our study. As repeat angioplasty becomes more accepted, it is likely that an increased proportion of such patients will choose repeat angioplasty rather than bypass surgery.

Our success rate $(93 \%)$ and restenosis rate $(34 \%)$ after third angioplasty accord with those of other centres. Terstein et al reported on 74 patients undergoing a third angioplasty. ${ }^{11}$ Primary success was achieved in $69(93 \%)$ patients and there was restenosis in $28(41 \%)$. Jolly et al reported primary success in $33(92 \%)$ of 36 patients and recurrence in $11(33 \%) .^{10}$ Abi-Mansour et al documented restenosis in four $(24 \%)$ of 17 patients after a successful third angioplasty. ${ }^{12}$ Accordingly, it seems that the primary success rate, complication rate, and restenosis rate after a third angioplasty are similar to those after first or second angioplasty.

A further angioplasty was deemed to be technically feasible in all 12 patients in our study who eventually had elective coronary bypass surgery. Indeed, in all, the decision to proceed to bypass surgery rather than attempt a further angioplasty seemed to be determined more on the basis of patient and/or physician preference rather than angiographic factors.

We applied a hypothetical management model to our study to see what the outcome of treating these patients with repeated angioplasty would be. This model limited the maximum number of angioplasties performed in any one patient to five and assumed restenosis rates of approximately $20 \%, 30 \%, 35 \%$, $50 \%, 50 \%$ for successive angioplasties. The general success rate for a second or subsequent angioplasty was assumed to be approximately $94 \%$. Application of this schema to a hypothetical population of 1000 patients with a successful initial angioplasty (figure) forecasts that at some time primary success at angioplasty will not be obtained in 17 patients and that four patients will need five procedures to achieve long lasting revascularisation. Overall, coronary angioplasty will eventually fail in $21(2.1 \%)$ of the hypothetical cohort of 1000 patients.

Whatever the projected outcome not all patients will be prepared to undergo repeated redilatations, and some will elect for revascularisation with coronary graft bypass surgery. Similarly, the development, within individual patients, of progressively more severe lesions with each subsequent redilatation may make further attempts at redilatation more difficult and they will eventually need bypass operations. In addition, the occurrence of progressively more complex as well as more severe lesions with successive redilatations may increase the restenosis rate because of greater vessel damage. This latter consideration may, in part, account for the increasing restenosis rate seen, with each subsequent redilatation, in our study patients. 
488

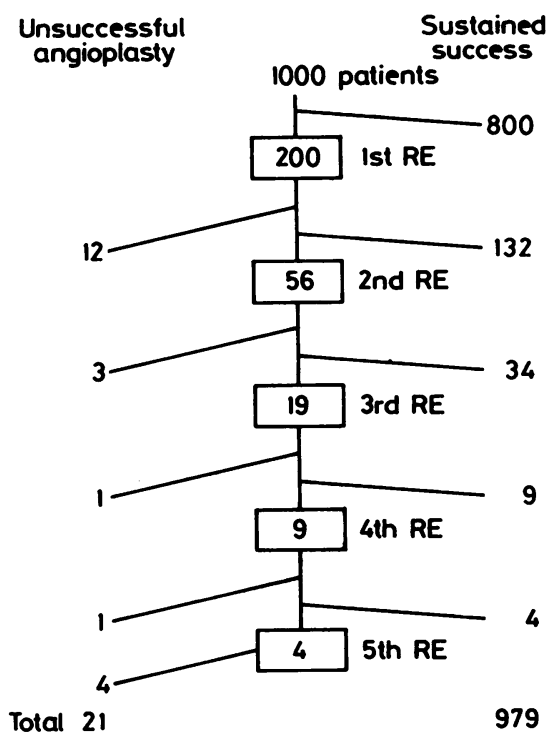

Fig 1 Hypothetical model for the management of restenosis with angioplasty only. This was applied to a hypothetical cohort of 1000 patients with successful initial angioplasty. The assumptions on which this model is based are detailed in the text. RE, restenosis.

Although our experience suggests that recurrent restenosis may be managed successfully with repeated redilatations, the cost effectiveness of such a management strategy must also be considered. Several studies have compared the cost effectiveness of initial revascularisation with coronary angioplasty and with that of coronary graft bypass surgery. ${ }^{1314}$ The results of these studies indicate that over a follow up period of 12 months angioplasty is the more cost effective method. ${ }^{1314}$ We do not know, however, whether the additional costs and long term outcome of patients undergoing two or more redilatations for recurrent restenosis are equivalent to those in patients who have bypass surgery after developing a second restenosis. These issues will have to be fully investigated before definitive guidelines on the management of recurrent restenosis can be drawn up.

Coronary balloon angioplasty is increasingly used as an alternative to coronary bypass graft surgery in the treatment of selected patients with coronary occlusive disease. ${ }^{4}$ Indeed, in the United States, the number of coronary angioplasty procedures performed increased from 39000 in 1983 to nearly 150000 in 1987 (report from the Committee for Professional and Hospital Activities, Ann Arbor, Michigan). Despite the low incidence of recurrent restenosis the volume of coronary angioplasty procedures will increase the number of patients with repeat restenosis in the next few years. To date, there have been
Glazier, Varricchione, Ryan, Ruocco, Jacobs, Faxon $\stackrel{\text { m }}{\stackrel{\square}{\Phi}}$ few guidelines on the management of patients with recurrent restenosis. Our experience suggests that ${ }_{c}^{7}$ patients are generally best treated by repeat angioplasty. Although some of our patients with recurrentos? restenosis were eventually treated with coronaryo bypass surgery, most remained symptom free at long을 term follow up after a third, fourth, or even fifth $\frac{\bar{c}}{\partial}$. angioplasty.

\section{References}

1 Gruentzig AR, Myler RK, Hanna EH, Turina MI $\overrightarrow{\vec{\omega}}$ Coronary transluminal angioplasty [Abstract]. Cir culation 1977;55-56(suppl III):III-84.

2 Gruentzig AR. Transluminal dilatation of coronaryo artery stenosis. Lancet 1978;i:263.

3 Gruentzig AR, Senning A, Siegenthaler WE. Non: operative dilatation of coronary artery stenosis: per-o cutaneous transluminal coronary angioplasty. $N$ Engb J Med 1979;301:61-8.

4 Myler RK, Shaw RE, Stertzer SH, Clark DA, Fishman J, Murphy MC. Recurrence after coronary angio plasty. Cathet Cardiovasc Diagn 1987;13:77-86.

5 Holmes DR, Vliestra RE, Smith HC, et al. Restenosiso after percutaneous transluminal coronary angioplasty ${ }^{\circ}$ (PTCA): a report from the PTCA registry of the National Heart, Lung and Blood Institute. $\mathrm{Am}$ Cardiol 1984;53:77C-81C.

6 Leimgruber PP, Roubin GS, Hollman J, et al. Resten osis after successful coronary angioplasty in patients with single vessel disease. Circulation 1986;73:710-8. $\frac{.}{8}$

7 Meier B, King SB III, Gruentzig AR, et al. Repeat coronary angioplasty. J Am Coll Cardiol 1984;4을 463-6.

8 Williams DO, Gruentzig AR, Kent KM, Detre KM, Kelsey SF, To T. Efficacy of repeat percutaneous? transluminal coronary angioplasty for coronary restenosis. Am J Cardiol 1984;53:32C-5C.

9 Black AJR, Anderson HV, Roubin GS, Powelson SW Douglas JS, King SB III. Repeat coronary angioplasty: correlates of a second restenosis. J Am Colt Cardiol 1988;4:714-8.

10 Jolly $\mathrm{P}$, Bonan R, Palisaitis D, et al. Treatment of recurrent restenosis with repeat transluminal coron-0 ary angioplasty. Am J Cardiol 1988;61:906-9.

11 Terstein PS, Hoover C, Lignon B, et al. Repeat restenosis: efficacy of the third and fourth coronary. angioplasty [Abstract]. J Am Coll Cardiol 1987\} 9:63A.

12 Abi-Mansour $P$, Whitworth HB, Hoffmeister J Douglas JS, King SB. Initial and late outcome after $x^{\omega}$ third coronary angioplasty (PTCA) for recurren native coronary artery stenosis [Abstract]. Circulationo 1985;72(suppl II):III-141.

13 Kelly ME, Taylor GJ, Moses HW, et al. Comparative? cost of myocardial revascularisation: percutaneous transluminal angioplasty and coronary artery bypasso surgery. J Am Coll Cardiol 1985;5:16-20.

14 Reeder GS, Krishan I, Nobrega FT, et al. Is percutan $\frac{\rho}{\mathbb{T}}$ eous coronary angioplasty less expensive than bypass surgery? N Engl J Med 1984;311:1157-62. 